\title{
Competência da Anvisa e a regulamentação da propaganda
}

Tercio Sampaio Ferraz Junior*

Este artigo trata do tema da competência da Anvisa para efetuar, mediante atos administrativos, o monitoramento e controle da propaganda, publicidade e informação de alimentos.

\section{Da competência da Anvisa em seu quadro constitucional}

A propaganda, em face da competência da Anvisa, vem disciplinada pela Lei no 9.782/1999, que dispõe:

Art. $6^{0}-\mathrm{A}$ agência terá por finalidade institucional promover a saúde da população, por intermédio do controle sanitário da produção e comercialização de produtos e serviços submetidos à vigilância sanitária, inclusive dos ambientes, dos processos, dos insumos e das tecnologias a eles relacionadas, bem como o controle de portos, aeroportos e de fronteiras.

Tendo em vista a competência da União, no âmbito do Sistema Nacional de Vigilância Sanitária (art. 2o), para “III - normatizar, controlar e fiscalizar produtos,

\footnotetext{
* Professor titular da Faculdade de Direito da Universidade de São Paulo (USP).
} 
substâncias e serviços de interesse para a saúde" e para "VII - atuar em circunstâncias especiais de risco à saúde", estabelece a lei a seguinte competência:

Art. $7^{\circ}$ - Compete à agência proceder à implementação e à execução do disposto nos incisos II e VII do art. 2o desta lei, devendo: (...) XXVI - controlar, fiscalizar e acompanhar, sob o prisma da legislação sanitária, a propaganda e publicidade de produtos submetidos ao regime de vigilância sanitária (redação dada pela Medida Provisória no 2.190-34, de 23 de agosto de 2001, grifo do autor).

A propaganda comercial tem por objeto a publicidade de produtos e serviços em veículos ou processos de comunicação. O primeiro sentido de propaganda comercial é tornar público, isto é, comum e transparente. Propaganda comercial sem exteriorização não é atividade econômica. "Propaganda" interna é mera publicidade direta de bem ou serviço pelo próprio fabricante ou comerciante. Não é atividade mediatizada pela propaganda comercial. $\mathrm{O}$ segundo sentido da propaganda, atividade comercial, é, nesses termos, venda através de meios de comunicação de massa. É a comunicação da informação do produto por intermédio daqueles meios, com o propósito de vendê-los. Não é a publicidade realizada pelo próprio anunciante, no seu local de venda ("propaganda" interna).

Distingue-se, assim, a propaganda comercial da publicidade como meio para a venda pessoal (Kirkpatrick, 1997:26). Primeiro, a propaganda comercial, ou atividade-meio, é mensagem que se dirige a muitos simultaneamente, já a publicidade de venda pessoal, pelo próprio anunciante, atinge poucos de cada vez. Segundo, a mensagem de propaganda comercial é veiculada por um meio de comunicação de massa - TV, rádio, imprensa, outdoor - , enquanto a publicidade de venda pessoal é enviada diretamente, no contexto em que ocorre a venda.

No caso de alimentos, o Decreto-lei no 986/1969, define propaganda como “a difusão, por quaisquer meios, de indicações e a distribuição de alimentos relacionados com a venda e o emprego de matéria-prima alimentar, alimento in natura, materiais utilizados no seu fabrico ou preservação, objetivando promover ou incrementar o seu consumo" (art. 2o, inciso XIV).

A propaganda não deixa de ser uma forma de comunicação, realizada por pessoa física ou jurídica, pública ou privada, no exercício de uma atividade comercial, industrial, artesanal ou profissional, com o intuito de promover ou estimular a aquisição de produtos. Como tal, a propaganda é atividade econômica lícita, protegida, pois, pelo disposto no parágrafo único do art. 170 da $\mathrm{CF}$, cujo teor é o seguinte: "É assegurado a todos o livre exercício de qualquer atividade econômica, independentemente de autorização de órgãos públicos, salvo nos casos previstos em lei", e a ressalva refere-se a atividades que exigem competência técnica, im- 
prescindível para o seu exercício. Nesse sentido, a propaganda comercial é objeto de uma competência legislativa própria (CF art. 22, XXIX).

Mas ao fazê-lo, a Constituição consagrou o mercado e a dinâmica dos agentes privados como a força motriz por excelência da economia, na crença consistente de que as soluções geradas pelos agentes privados sobre o que, como e quanto produzir são as mais aptas à produção de bem-estar (Nusdeo, 2001:113-121). Note-se que a atuação do Estado passa a ter um caráter negativo, isto é, de identificação e colocação dos limites aos agentes privados.

Logo, não exerce orientações positivas sobre os negócios, o que somente poderia ser indicativo, mas jamais determinante para as empresas (art. 174, caput), restringindo-se a apontar quais ações ou operações privadas não serão aceitas, quando essas ofenderem ou ameaçarem interesses públicos relevantes como a saúde, a livre competição, a segurança, o meio ambiente, o pleno emprego etc. As orientações positivas sobre a organização dos negócios, dentro da lei, devem partir sempre dos próprios agentes, por força da livre iniciativa que fundamenta e informa todo o sistema econômico.

Essa regra vale também para a atividade de propaganda de produtos e serviços, de forma que a livre iniciativa é o primeiro elemento que a autoriza e informa.

Mas, concomitante à liberdade de iniciativa, a atividade de propaganda fundamenta-se na liberdade de expressão. Assim, essa derivação da liberdade de propaganda a partir da liberdade geral de iniciativa não é necessária, considerado o disposto no art. 220 da CF, que expressa a positivação constitucional dessa liberdade aplicável ao agente econômico e que permite falar até mesmo em um direito à liberdade de propaganda. É esse o teor que se encontra no seu caput: "Art. 220 - A manifestação do pensamento, a criação, a expressão e a informação, sob qualquer forma, processo ou veículo não sofrerão qualquer restrição, observado o disposto nesta Constituição".

Não há dúvida que essa liberdade fundamental de expressão aplica-se também a pessoas jurídicas, tema já pacificado na doutrina nacional e internacional. José Afonso da Silva (1999:195), por exemplo, entende que "a pesquisa no texto constitucional mostra que vários dos direitos arrolados nos incisos do art. 5o se estendem às pessoas jurídicas". Vale ressaltar, inclusive, que o direito comparado nos aponta para a propriedade dessa extensão dos direitos fundamentais às pessoas artificiais. O art. 19, alínea 3, da Lei Fundamental alemã (Grundgesetz für die Bundesrepublik Deutschland): "Os direitos fundamentais valem igualmente para pessoas jurídicas nacionais, na medida em que, pela natureza, lhes sejam aplicáveis". Ao comentar esse artigo, Dreier e colaboradores (1996) enumeram liberdades asseguradas também às pessoas jurídicas, entre as quais a liberdade de expressão, prevista no art. 5o, alínea 1, da Lei Fundamental alemã. No mesmo sentido, Canotilho (1998:384) também sustenta que 
a extensão dos direitos e deveres fundamentais às pessoas colectivas (pessoas jurídicas) significa que alguns direitos não são "direitos do homem", podendo haver titularidade de direitos fundamentais e capacidade de exercício por parte de pessoas não identificadas com cidadãos de "carne e osso".

Como direito fundamental previsto constitucionalmente, a liberdade de expressão não pode ser eliminada por norma legal.

Ao Estado atribui-se a função de proteger a liberdade e jamais de cerceá-la. Qualquer intervenção que possa afetar a liberdade deve, antes de tudo, estar pautada por regras claras e públicas, que permitam ao indivíduo planejar seu próprio curso de vida, ciente das consequências jurídicas de seus atos. Daí a exigência contida no princípio de legalidade, segundo a qual, "ninguém será obrigado a fazer ou deixar de fazer alguma coisa, senão em virtude de lei" (CF, art. 5o, inc. II).

Mas o exercício da liberdade de expressão pode ser delimitado e restringido, nos termos admitidos pela própria Constituição.

Os limites da liberdade estabelecidos por lei são, nesses termos, compatibilizações e nunca impedimentos. Isto é, devem ser entendidos como acomodações harmônicas entre os diferentes exercícios da liberdade de expressão. Porque a Constituição e só ela dá o sentido jurídico da liberdade como núcleo da dignidade em uma sociedade fraterna, cabe à lei apenas regular seu exercício para proteção da própria pessoa, em termos de equilibrar a liberdade de uma pessoa em face da liberdade de outra, para permitir a convivência. Ou seja, a liberdade só pode ser restringida no sentido de instaurar uma harmonia, não podendo ser, em nenhuma hipótese, eliminada. Note-se, a propósito, que a Constituição brasileira veda taxativamente a prisão perpétua, posto que isto não significaria restrição, mas eliminação da liberdade (Constituição Federal, art. 5o, inciso XLVII, alínea b). Nesses termos, só a própria Constituição pode estabelecer competências restritivas, na forma de exceções a esse direito.

No tocante à propaganda, por exemplo, serão estabelecidas legalmente (ver, por exemplo, a CF art. 220, §4: "sujeita a restrições legais"), nos casos que discrimina especificamente. Quanto à propaganda comercial, em princípio, a atividade-meio está sujeita à livre negociação. A proteção do consumidor em relação à propaganda decorre de efeitos indiretos que ela causa sobre ele. Entende-se assim que, em vista do consumidor, a propaganda possa subordinar-se a requisitos gerais, como os que são estabelecidos pelo Código de Defesa do Consumidor, em seu art. 36.

Distinga-se, pois, em primeiro lugar, o caso de abuso no exercício do direito (liberdade de propaganda), quando pode ocorrer uma restrição do seu próprio conteúdo, por caracterizar uma infração (contra as relações de consumo, contra a 
concorrência, contra o meio ambiente). Entende-se aí sua regulação, tendo em vista a proscrição da propaganda enganosa, subliminar, contrária à dignidade humana, com repercussões negativas sobre a saúde etc. (Código de Defesa do Consumidor, art. 37: propaganda enganosa ou abusiva).

Mas há outra forma de regulação, que não lida com abuso, mas com a propaganda de produtos, práticas e serviços que podem ser nocivos (à saúde, ao meio ambiente), para os quais compete à lei federal estabelecer os meios legais para garantir à pessoa e à família a possibilidade de se defender (CF, art. 220, §3o, inciso II). Nesse sentido, a competência prevista no $3^{\circ}{ }^{\circ}$ do art. 220 da CF88 exige, para a disciplina dessa matéria, lei federal.

Nesse caso, a competência legislativa federal visa assegurar aos consumidores de publicidade que suas decisões sejam baseadas em informações suficientes para a formação do juízo. Não cabe ao legislador substituir a pessoa e a família nessa defesa, mas sim dar-lhes os meios para a defesa. Dar-lhes os meios legais para se defenderem não é a mesma coisa que defendê-las. Quem se defende é a própria pessoa e a própria família, com os meios legais postos à sua disposição. Não pode, pois, a lei subtrair-lhes a liberdade na formação do seu próprio juízo.

Exclui-se, pois, qualquer restrição, observado o disposto na Constituição e a censura, sob qualquer forma (CF art. 220, caput e $\$ 2^{\circ}$ ). Liberdade, nesses termos, opõe-se à tutela estatal. Ninguém, a não ser o próprio homem, é senhor de sua consciência, do seu pensar, do seu agir, estando aí o cerne da responsabilidade. Cabe ao Estado propiciar as condições desse exercício, mas jamais substituir o ser humano na definição das escolhas e da correspondente ação.

Não pode o Estado, nesse sentido, degradar o ser humano à condição de incapaz, por si só, de discernir entre o bem e o mal. Cabe ao Estado dar-lhe os meio legais para exercer o juízo sobre as coisas, mas não pôr-se em seu lugar, para dizer o que sua consciência distingue e aprova ou desaprova. Se o Estado tutela a consciência e a deliberação individual, a condição humana é degradada pelo dirigismo próprio dos regimes totalitários. O Estado que exerce tal forma de tutela destitui o cidadão da possibilidade de responsabilizar-se pelos seus atos, do lado do que supostamente protege, destitui-o da capacidade de julgar. Assim, embora a CF assegure o direito à saúde como um direito social, ninguém pode ser obrigado a preservar a própria saúde. Isto conduz a importantes questões, como a duvidosa imposição de transfusão de sangue a quem, por motivos íntimos (religiosos), a ela se opõe. Mas é possível qualificar certas práticas referentes a determinados produtos como ilícitas: por exemplo, o tráfico de entorpecentes e drogas afins (CF art. 5으, XLIII). Nesse caso, a lei considerará crime inafiançável "o tráfico ilícito". Isso toca de perto a proteção da saúde contra a propaganda de produtos que possam ser nocivos à saúde.

Logo, se um produto é admitido como nocivo, nada impede que o legislador venha a restringir-lhe a produção, a venda, a comercialização e, consequentemen- 
te, a sua propaganda. Não há propaganda de produto cujo tráfico é ilícito (maconha, cocaína etc.).

Não é disso, porém, que trata o §3ํ do art. 220 da CF/88. Se o produto é lícito, mas pode ser nocivo à saúde, cabe à lei pôr à disposição da pessoa e da família os meios legais para se defenderem. Tais meios legais são, por exemplo, constituídos de padrões de qualidade dos produtos veiculados em propaganda, que podem ser utilizados na avaliação posterior de eventual responsabilidade civil por danos materiais e morais causados pela publicidade. Ou seja, a Constituição encara essa potencialidade (nocividade) como um atributo suficiente não para proibir-lhe a propaganda, mas para estabelecer os meios legais para avaliação de responsabilidades. Na verdade, o produto de que ali se trata não é proibido, mas pode, sob certas condições, tornar-se nocivo. Isso depende de sua composição, do seu processo de produção, das condições de comercialização. Assim, cabe à lei conferir à autoridade a competência para estabelecer os padrões adequados para discriminar os requisitos técnicos cuja violação os torna nocivos à saúde e cuja veiculação em propaganda pode gerar responsabilidade. Por exemplo, se um produto deve obedecer a requisitos sanitários de produção, cuja violação pode causar danos à saúde, sua propaganda pode ser controlada pela autoridade, para verificar sua veiculação desavisada, do que pode resultar responsabilidade. Tais meios legais, contudo, não devem ferir a liberdade de informação, como se observa pela declaração de inconstitucionalidade do $\S 2$ o do art. 247 do Estatuto da Criança e do Adolescente, que autorizava a autoridade judiciária a apreender a publicação ou a suspender a programação da emissora que veiculasse o conteúdo impróprio (ADin nº 8692/DF: Informativo STF, no 156).

Diferente é o cuidado com produtos, cuja nocividade decorre diretamente de seu uso, presumido como maléfico à saúde. Isso fica claro no dispositivo do parágrafo seguinte $\left(\$ 4^{\circ}\right)$, que enumera produtos cuja nocividade do consumo (uso) é taxativamente afirmada e para os quais a propaganda conterá, sempre que necessário, advertência sobre os malefícios de seu uso. A propaganda desses produtos (tabaco, bebidas alcoólicas, agrotóxicos, medicamentos e terapias) está sujeita a restrições legais, "nos termos do parágrafo anterior".

É importante entender corretamente o disposto nesses dois parágrafos. Ambos se destinam, imediatamente, à propaganda do produto e, apenas mediatamente, ao produto. $\mathrm{O}$ produto, contudo, ainda que indiretamente, é atingido de modo diferente por ela. No caso do $\S 4^{\circ}$, o problema está no uso do produto, que é, presumidamente, considerado maléfico. Por isso a Constituição autoriza restrições à sua propaganda, independentemente da existência de padrões de qualidade, aptos a aferir-lhes a nocividade. Nos casos do $\S 3^{\circ}$, trata-se do produto, em face de padrões definidos para a sua produção e comercialização. Nesse sentido, a Constituição autoriza, mediante lei, o controle e a fiscalização da propaganda para verificar, no 
produto veiculado, o cumprimento das exigências sanitárias, cuja desobediência pode gerar nocividade à saúde. No primeiro caso, por exemplo, o uso do cigarro, quando considerado maléfico, deve ter sua propaganda restringida ("restrições legais"), para que o consumo não seja estimulado. Daí, por exemplo, a proibição de aliar o consumo do cigarro ao esporte e a esportistas. Já no segundo caso, a propaganda não pode ser restringida, mas submetida a meios legais que garantam ao consumidor (à pessoa e à família) a possibilidade de se defender, por exemplo, pelo controle das condições sanitárias do produto propagado.

De resto, a competência do Estado com respeito à saúde, o correspondente direito deve ser garantido "mediante políticas sociais e econômicas que visem à redução do risco de doenças e de outros agravos" (CF, art. 196 - grifo do autor), no sentido de cuidar da saúde e assistência social, competência comum a todos os entes federativos (CF, art. 23, II), aí incluídas as políticas de educação por meio de orientação pedagógica e mediante campanhas publicitárias do próprio ente público.

\section{Competência da Anvisa quanto à propaganda}

Desses dispositivos decorrem alguns importantes limites à competência da Anvisa no que se refere à propaganda (Lei no 9.782/1999, art. 7oㅡ, XXVI). Como princípio orientador do seu entendimento, de acordo com Maximiliano (1997:313), deve-se ter em conta que: "interpretam-se estritamente os dispositivos que instituem exceções às regras gerais firmadas pela Constituição", sendo esse o caso daqueles que "cerceiam, embora temporariamente, a liberdade, ou as garantias da propriedade".

Sendo a propaganda alcançada pela livre iniciativa, como fundamento da República, a atividade de propaganda pode ser regulada por lei, mas para estabelecer meios para garantir à pessoa e à família a possibilidade de se defenderem da propaganda de produtos que possam ser nocivos à saúde. Ressalvados os produtos enumerados no art. 220, $\$ 4^{\circ}$ da CF (tabaco, bebidas alcoólicas etc.), cujo malefício do uso é presumido, a nocividade à saúde dos demais deve ser objeto de delimitação legal, interpretada estritamente.

\section{Agências reguladoras: poder normativo e limites à competência}

Por tratar-se, inicialmente, de competência conferida a uma agência reguladora, é importante estabelecer os limites dessa competência delegada.

Recentemente, o direito administrativo brasileiro incorporou um instrumento do direito norte-americano: as agências reguladoras. A nova entidade é considerada "autarquia especial", por causa de poderes ampliados que detém, em com- 
paração com a simples autarquia. Sua principal característica, nesse sentido, é a independência (quanto a decisão, objetivos, instrumentos, financiamento). Por conta dessa característica, ocorre, com a criação de agências, uma ostensiva delegação de poderes, uns quase legislativos, outros quase judiciais e outros quase regulamentares. Tal delegação, obviamente, levanta sérias dificuldades no que toca ao fundamento constitucional.

Exatamente por conta da prevalência da livre iniciativa como fator propulsor da economia, mas que precisa ser amparada quanto à possibilidade de abuso e restrita em função de outros interesses públicos relevantes, como a proteção à saúde, é que a Constituição de 1988 traz uma redefinição do papel do Estado, que acarreta importantes reflexos quanto à interpretação da legalidade dos atos administrativos.

As agências, no Brasil, surgem por conta do processo de privatização e da disciplina das concessões. Assim, aparecem como um novo instrumento de atuação do Estado no domínio econômico. Diz-se que elas representam a substituição do modelo de gestão com base em controles formais (legalidade e motivação fundamentada) e na intervenção direta (Estado empresário), pelo modelo gerencial, com base em avaliação de desempenho (eficiência) e intervenção condicionante da eficiência (regulação e regulamentação). Ou seja, nem o Estado mínimo, protetor das liberdades (Estado de direito liberal), nem o Estado promotor de benefícios sociais e econômicos (Estado social), mas o Estado regulador que contribui para o aprimoramento das eficiências do mercado (Estado regulador).

A doutrina pátria administrativa e constitucional reconheceu imediatamente o obstáculo representado pela reserva legal ao poder regulamentar das agências, buscando a construção de seu fundamento constitucional, bem como a identificação de balizas claras para seu exercício. A solução, a meu ver, consiste em interpretar o poder regulamentar como uma forma de delegação inominada, com a função de estabelecer normas de implementação ou complementação de leis-quadro (lois cadre) que contenham princípios e diretrizes gerais. Não se trata propriamente de uma delegação legislativa, pois não implica abdicação pelo legislador de sua competência. Simplesmente o uso de conceitos indeterminados pelo legislador confere uma margem de discricionariedade à agência na interpretação, aplicação e regulamentação complementar das leis às quais a agência se submete.

Nesse contexto, o papel da interpretação, no estabelecimento de atos administrativos, toma outra feição. Ao invés de mero limite negativo, adquire um sentido positivo. Interpretar não é simplesmente declarar, tornar claro, mas revelar o sentido apropriado para a vida real, conducente a uma decisão reta. Cabe ao aplicador da lei (juiz, autoridade administrativa ou homem em particular) enquadrar o fato humano em uma norma jurídica, para isso é indispensável compreendê-la bem, ou seja, interpretá-la (Maximiliano, 1997:10-13). 
Obviamente, no âmbito de suas faculdades, a administração permanece ligada às intenções do legislador. Os agentes públicos, assim, vinculam-se a elas no sentido de poder e dever guiar-se pela ideia de satisfazer o melhor possível a necessidade protegida, mas também sem afetar de forma desarrazoada outros interesses que também merecem proteção. A partir disso, a administração interpreta e expede seus atos. Existe, então, um conduzir-se de acordo com a opinião interpretativa do estabelecido em lei, que objetivamente reputam a melhor, em face das situações de fato.

Na busca da melhor apreciação/interpretação, essa qualidade hermenêutica dos juízos deve ser limitada. O bom administrador, colocado em face de certas circunstâncias e guiado pela ideia de satisfazer certa necessidade, submete-se a uma regra geral de razoabilidade (relação entre as circunstâncias e a consideração do fim a atingir).

Em termos de limites da administração para a expedição de atos gerais que envolvam interpretação da lei, há de se entender que a administração deve atingir objetivamente o interesse público e se determinar apenas por esse interesse. $\mathrm{O}$ interesse público não deve apenas ser realizado, mas o agente deve estar convencido de que vai realizá-lo da melhor maneira. $\mathrm{O}$ ato administrativo há de ser considerado irregular ou ilegal se for demonstrado que é fruto do juízo interpretativo da administração acerca da ideia de com ele satisfazer outra necessidade, pública ou privada, fora do âmbito de sua competência. Demonstrada essa intenção, demonstrado o desvio intencional do poder atribuído ao seu destino natural, o ato deve julgar-se viciado. O objetivo é combater o arbítrio.

Aparece aqui a questão da discricionariedade. Essa margem ampliada de discricionariedade, advinda de uma interpretação e regulamentação positiva de loiscadre, deve encontrar, porém, limites que legitimem seu exercício. Como ressalta Di Pietro (2002), se a competência normativa das agências tem lugar a partir de conceitos indeterminados trazidos pelas leis que a introduzem, o direito administrativo brasileiro está repleto de conceitos determinados, que colocam uma série de barreiras legais ao seu exercício.

Não só a justificação como também os limites do papel normativo são dados pelo princípio de eficiência dos atos administrativos, inserido pela Emenda Constitucional no 19/1998, que possibilita uma reinterpretação do princípio de legalidade, em termos de uma legitimação finalística dos atos administrativos (CF art. 37), isto é, os atos são legítimos desde que alcancem os objetivos estabelecidos em lei de forma proporcional. ${ }^{1}$

\footnotetext{
${ }^{1}$ Como procuramos ressaltar no trabalho "Agências reguladoras: legalidade e constitucionalidade", o advento do Estado regulador provoca aquilo que Karl Lowenstein chama de processo de "mutação constitucional" que não se reflete no texto, mas provoca a releitura da Constituição. Essa transformação
} 
Assim, o sentido moderno da legalidade vê na lei não tanto uma condição e um limite, mas, basicamente, um instrumento de exercício da atividade administrativa. Como instrumento, seu princípio hermenêutico está na solidariedade entre meios e fins, daí a razoabilidade da atividade administrativa, é submetida, então, a uma avaliação de sua eficiência. Nesses termos, o respeito à legalidade exige do intérprete uma distinção entre conceitos indeterminados e discricionários, bem como uma concepção da discricionariedade que não se limita a um juízo de oportunidade, mas alcança os juízos de realidade (avaliação de políticas de implementação de objetivos e, por conseguinte, de adequação dos meios escolhidos em face dos fins propostos).

O princípio da eficiência tem por fim disciplinar a atividade administrativa nos seus resultados, tornando possível a legitimação (mas também a responsabilização) dos atos administrativos por seu êxito em atingir os fins pretendidos por lei. Assim, a validação do ato pelo princípio de eficiência tem estrutura finalística (validação pela obtenção do resultado pretendido por lei) e não condicional (validação pelo preenchimento das condições previstas em lei para realização do ato, independentemente de seu resultado).

Ao adquirir essa estrutura finalística pautada pelo êxito em implementar determinadas políticas públicas, a discricionariedade, que se tornou mais ampla, ganha também um sentido técnico, que representa uma importante limitação e a sujeita a controle (diz-se que a discricionariedade das agências é uma discricionariedade técnica). Se pela legalidade estrita bastava ao administrador cumprir os requisitos formais para que emitisse seu ato de escolha, oportuna e conveniente, entre o leque de alternativas aberto pela lei, a legalidade finalística o vincula a uma otimização de sua solução para preenchimento dos conceitos e diretrizes legais. E quando se fala em otimização, na esteira do princípio de eficiência, entra em cena não só o êxito na execução dos objetivos legais (adequação), como também a ponderação dos meios em termos de necessidade (proibição de excesso), de redução dos custos impostos aos administrados e de ponderação de outros direitos e liberdades individuais envolvidas (proporcionalidade em sentido estrito).

Essas três regras - adequação, necessidade e proporcionalidade estrita têm recebido atenção recente dos constitucionalistas na forma de desdobramento do já chamado princípio de proporcionalidade no esforço de interpretação da constitucionalidade das leis. Ocorre, porém, como bem chama a atenção Virgílio Afonso da Silva (2002), que tais regras são parâmetros hermenêuticos, cuja análise está

real na concepção do Estado cria condições para a recepção do instituto das agências reguladoras. Em particular, cria condições para uma releitura do princípio de legalidade, a partir do princípio de eficiência (CF art. 37). 
presente na interpretação de qualquer ato normativo, legal ou infralegal, quando se coloca em questão sua conformidade com norma superior.

Para precisar os limites desse poder discricionário nos atos das agências reguladoras, parece apropriado entender que a discricionariedade admite, num campo de possibilidades fáticas, a escolha de objetivos e a exigência de meios correspondentes, pedindo-se comprovação da eficiência das medidas tomadas. Por presunção, em termos de eficiência, a atividade é considerada livre, salvo quando vinculada estritamente (absoluta reserva de lei). Essa liberdade, porém, não é igual à liberdade privada, pois imputa ao administrador não o interesse social como um limite ao interesse privado, mas o interesse público como objetivo de realização, daí a razoabilidade das medidas tomadas (proporcionalidade, proibição de excessos, compatibilidade técnica e política). Trata-se de uma liberdade de escolha, conteúdo de uma competência (discricionária), delegada por lei no sentido de atuação conformada à solidariedade entre meios e fins (legalidade por legitimação).

A partir dessas premissas, podem ser delineados os limites da discricionariedade dos atos normativos da Anvisa como agência reguladora, na interpretação e aplicação das restrições legais à liberdade de propaganda. Entre eles, podem ser mencionados os seguintes:

sujeitam-se tais atos a interpretar/aplicar as restrições estabelecidas em lei à propaganda, interpretada restritivamente, não podendo ampliar restrições legais (legalidade estrita);

devem ser adequados às diretrizes traçadas na Lei oㅡ 9.782/1999 (adequação) e sua interpretação deve ser pautada pelo objetivo da política de Estado em disponibilizar ao indivíduo os meios legais para proteger-se da propaganda de produtos que podem ser nocivos;

somente se legitimam quando necessários para a persecução daqueles objetivos (necessidade);

não devem afetar de forma não razoável ou desnecessária outros direitos fundamentais envolvidos do administrado, em particular a livre iniciativa dos produtores e comerciantes de cigarros na implementação da organização que julgue mais adequada de seus ativos (proporcionalidade estrita).

\section{Controle da propaganda pelo prisma da legislação sanitária}

A primeira consequência daí está na delimitação da competência reguladora da Anvisa, referente à propaganda. Ela deve estar adstrita ao controle, fiscalização e acompanhamento da propaganda e publicidade, pelo prisma da legislação sanitária, de produtos e serviços submetidos à vigilância sanitária. 
Em primeiro lugar, é preciso entender o que significa, em especial no que diz respeito a alimentos, a expressão submetidos à vigilância sanitária.

Trata-se do controle sanitário da produção e da comercialização de certos e determinados produtos, aqueles que envolvam risco à saúde pública (Lei no 9.782/1999, art. 8oㅡㄴ caput: incumbe a agência, respeitada a legislação em vigor, de regulamentar, controlar e fiscalizar os produtos e serviços que envolvam risco à saúde pública). $\mathrm{O}$ $\S 1^{\circ}$ desse artigo enumera os bens e produtos submetidos ao controle e fiscalização sanitária pela agência. Pode-se entender que tais bens e produtos sejam aqueles que, eventualmente, envolvam risco à saúde pública. Entre eles, constam os alimentos (§1으, II - alimentos, inclusive bebidas, águas envasadas, seus insumos, suas embalagens, aditivos alimentares, limites de contaminantes orgânicos, resíduos de agrotóxicos e de medicamentos veterinários).

No entanto, para que a propaganda de alimentos possa ser submetida à fiscalização e controle, é preciso que se defina em que sentido envolvem risco à saúde.

É importante assinalar, inicialmente, que a expressão envolver risco à saúde não é idêntica a ser nocivo à saúde. Um produto nocivo pode envolver risco à saúde, mas nem todo produto que envolve risco à saúde é nocivo. E só os produtos que podem ser nocivos são submetidos ao controle, fiscalização e acompanhamento de sua propaganda. Isso vale especialmente para alimentos.

Afinal, alimentos, em si, não são nocivos à saúde. Também não podem ser presumidos como tal, presunção que, como vimos, a CF autoriza apenas para os produtos do art. 220, §4을 a considerar maléfico o seu uso, vem daí, por exemplo, a exigência, quanto a bebidas alcoólicas, de que a publicidade contenha um alerta sobre os riscos do excesso no consumo. Já de acordo com o comando constitucional do art. 220, §3ํ, II, o cuidado com a propaganda é para o produto que pode ser nocivo à saúde. A competência da agência, em termos de propaganda, não se estende ao risco pelo uso do produto, isto é, pelo fato de se tratar de produtos cujo consumo mal orientado venha a envolver risco à saúde. Propaganda destinada a estimular o uso de produtos que envolvam risco à saúde deve ser objeto de políticas educacionais, mas não de restrições à propaganda.

O controle de propaganda de produto nocivo à saúde, portanto, não se refere a todo e qualquer produto submetido à vigilância sanitária, de que fala a lei. Para efeito desse controle, supõe-se a avaliação do produto, para o qual há autorização para a definição de padrões de identidade e qualidade (Decreto-lei no 9866/1969, art. 28), em que se dispõe, de um lado, sobre a denominação, definição e composição dos alimentos, matérias- primas alimentares, alimentos in natura e aditivos intencionais (identidade); e de outro, sobre requisitos de higiene, normas de envasamento e rotulagem (qualidade). Na lei, o produto alimentício pode envolver risco, no sentido sanitário, mas só poderá ser nocivo em razão da violação dos limites de contaminantes, resíduos tóxicos, desinfetantes, metais pesados e outros que envolvam risco à saúde, limites 
esses estabelecidos por normas e padrões técnicos. Portanto, de alimento obtido por processo tecnológico adequado e comercializado em condições adequadas. Por isso, a questão da propaganda.

Admite-se uma competência de controle da propaganda - em atenção à natureza sanitária - para produtos alimentícios, no que se refere à sua produção e comercialização. Competência de controle, nos termos do art. 174 da CF, enquadra-se no sentido do Estado como agente normativo e regulador. Controle tem o sentido forte de poder normativo e o sentido fraco de fiscalização. Autoriza-se assim o estabelecimento de normas, de que resulta a regulação da atividade de produção e de comercialização. Fiscalização, no sentido da função de fiscalização (art. 174), significa verificar o cumprimento das normas e da regulação, mas também de prevenção. Daí o sentido dado pela palavra vigilância. A delimitação da competência para o exercício do controle, da fiscalização e do acompanhamento da propaganda se dá pela especificação do seu conteúdo, isto é, visa especificadamente àquela propaganda de produtos que, submetidos a padrões de produção, devem informar sobre o seu atendimento e cuja desobediência manifesta uma possível nocividade.

Assim, a propaganda é alvo de ação da Anvisa no sentido de estabelecer normas e regulação que visem à publicidade de produtos obtidos por processo tecnológico, submetidos a registro e que atendam à rotulagem e a padrões de identidade e qualidade prescritos. O alvo da fiscalização, nesses termos, é evitar a propaganda de produtos alimentícios que, devendo ter sido registrados, não o foram, ou que, tendo sido registrados, podem não estar obedecendo à rotulagem ou a padrões de identidade e qualidade, podendo, então, ser considerados nocivos.

Nesses termos, não cabe à Anvisa exigir, mesmo de acordo com a lei, como faz no caso de produtos enumerados no art. 220, §4º da CF (tabaco, bebidas alcoólicas, agrotóxicos, medicamentos, terapias), cujo uso é considerado maléfico, por suas características intrínsecas, que sua propaganda contenha advertências, disciplinar e mesmo restringir a publicidade referente ao seu uso. O que lhe é permitido é controlar a propaganda de produtos alimentícios que possam ser considerados nocivos, controle este que visa detectar a violação dos limites de contaminantes, resíduos tóxicos, desinfetantes, metais pesados e outros que envolvam risco à saúde (Lei no 9.782/1999, art. 7으, IV).

Se, na competência para controlar, está o poder de editar normas, estas se restringem a regulamentar a propaganda estritamente nesse sentido e nesses termos.

Isso aponta para um limite na regulamentação da propaganda comercial, tendo em vista objetivos atribuídos à lei federal pelo art. 220, §3o da CF, ainda que relacionados com a saúde. Esse tipo de regulamentação normativa está inserido no campo das diversões e espetáculos públicos e refere-se aos meios de comunicação social. A competência conferida à União (lei federal) está em estabelecer meios legais para a autodefesa da pessoa e da família em face da propaganda de 
produtos que possam ser nocivos à saúde. Tratando-se de meios legais, à Anvisa, ao ser-lhe delegada determinada competência em lei própria, cabe tratar do tema exclusivamente de acordo com a legislação sanitária. Tratando de produtos submetidos à vigilância sanitária, a competência relacionada com a propaganda, ao falar de controle, só pode ser exercida em termos de exigir, por meio de normas, que a divulgação dos produtos que podem ser nocivos pela violação dos padrões de identidade e qualidade estabelecidos pela agência por força de lei, contenha meios para a autodefesa da pessoa e da família. Como, a CF aboliu qualquer tipo de censura proibitiva, mesmo para esses produtos, a possibilidade de regulamentar a informação, em relação às faixas etárias recomendadas, locais e horários em que sua publicidade se mostre inadequada, só pode ser estabelecida pela própria lei federal (Moraes, 2002:1.991).

Algo diferente é o cuidado sanitário com a adequação dos alimentos à saúde. Não se trata, aí, de propaganda de produtos que podem ser nocivos à saúde, nos termos da Constituição, mas de produtos que, dependendo de condições e formas de consumo, podem envolver risco à saúde. É um problema de educação alimentar, em que o risco para a saúde não está propriamente na nocividade do produto, mas sim nos hábitos alimentares.

Nada impede que a Anvisa promova, ela própria, campanhas educativas sobre dietas alimentares, mormente para orientação da família, através de publicidade em meios de comunicação (CF, art. 196 e art. 23-II). Mas não pode disciplinar a propaganda, estabelecendo para a atividade um planejamento compulsório (horários, advertências dietéticas etc.), até porque isso entraria nos limites estabelecidos pela Constituição Federal para a intervenção do Estado no domínio econômico, com o planejamento determinante para o setor público e indicativo para o setor privado e, assim mesmo, na forma da lei (CF, art. 174).

\section{Propaganda comercial: disciplina legislativa e autorregulamentação}

Em termos de propaganda, conduz diretamente às formas de autorregulamentação, como ocorre com as regras estabelecidas pelo Conar, em especial pelo Código Brasileiro de Autorregulamentação Publicitária.

Meios para a autoproteção são as imposições ao produtor do dever de esclarecer sobre a nocividade, de não incentivar o consumo, ao contrário, de orientar quanto ao consumo. Ou seja, a publicidade de produtos considerados nocivos, como forma de proteção ao indivíduo, passa a ser restrita a determinados espaços e, além do mais, segundo Lopes (1992:164) deve “deixar de ser meramente persua- 
siva, para realçar o seu caráter informativo, propiciando a livre escolha do consumidor e advertindo-o adequadamente na aquisição de produtos ou serviços, em particular os nocivos e perigosos". Nesse sentido, o disposto no Código de Defesa do Consumidor, art. 31 (e, de certo modo, art. 10, $\S 1^{\circ} \mathrm{e}$ e $\S 2^{\circ}$ ).

Em relação a produtos que não se enquadrem como aqueles que podem ser nocivos, mas cujos hábitos de consumo merecem orientações educativas e disciplina na sua propaganda, os meios de autoproteção ganham relevo.

Quanto a essa autorregulamentação, a experiência internacional comprova a eficiência dos mecanismos de autorregulação por parte dos agentes do mercado de propaganda.

Em geral, tanto na Comunidade Europeia quanto nos Estados Unidos da América, essa regulação se socorre fundamentalmente da autorregulamentação (Paz, 1994:302). No plano da autorregulamentação, mencione-se o Código Brasileiro de Autorregulamentação Publicitária (Conar) e o Código de Normas Padrão do Cenp.

Do ângulo do direito da concorrência, a possibilidade de se estabelecerem acordos, horizontais e verticais, entre agentes econômicos, é reconhecida na literatura e jurisprudência internacionais.

As cortes norte-americanas, em relação à publicação de padrões comuns e à emissão de juízos sobre a sua violação, reconhecem que, a princípio, toda associação com exigências à definição dos membros tem algum tipo de regras ou critérios limitativos e podem restringir, ao menos indiretamente, a concorrência no mercado.

Não obstante, a avaliação da legalidade de tais regras é feita com base na legitimidade econômica dos propósitos perseguidos por tal associação mediante a autorregulamentação, bem como na razoabilidade e objetividade das regras-padrão adotadas em relação aos propósitos assumidos. Se os padrões não forem objetivos e os propósitos não razoáveis, as regras serão consideradas ilegais, pois funcionariam como uma barreira à entrada no mercado, isto é, uma espécie de boicote persuadindo os adquirentes a não contratarem as empresas que não atingirem o padrão. Diante de tais elementos percebe-se que a conduta horizontalmente/verticalmente concertada na forma de acordos de autorregulamentação deve sempre ser analisada com base na regra da razão (Antitrust Law Developments - ABA, 1997:110-115).

Entre os parâmetros da jurisprudência norte-americana, considerados relevantes para determinar a razoabilidade e, portanto, reconhecer-se a legalidade do acordo de autorregulação, podem ser apontados os seguintes:

tratando-se de um ponto de vista concorrencial, o acordo deve ter algum propósito ou repercussão comercial, para que possa ser avaliado (St. Bernard Gen. 
Hosp. $v$ Hospital Serv. Association, 712 F.2d 978,988, $5^{\text {th }}$ Cir. 1983); no caso brasileiro, embora o relevo esteja na dimensão ética, existem repercussões no comportamento comercial dos subscritores do acordo;

os padrões definidos devem ser objetivos, isto é, suas regras devem ser impessoais (Radiant Burners v. Coke Co., 364 U.S. 656, 658, 1961); no caso, a destinação das regras conhece o requisito da impessoalidade, destinando-se a todos os participantes do mercado de propaganda;

os padrões adotados devem ser acessíveis também a não membros do acordo (Bogus v American Speech \& Hearng Association, 582 F2d. 277, 3d Circuit 1978); nesse caso, o acordo é de conhecimento de todo o mercado;

deve haver, além dos fornecedores de produtos ou serviços, a participação dos adquirentes na definição dos padrões de conduta e no juízo tomado a partir dos padrões definidos (Consolidated Metal Products $v$ American Petroleum Inst. 846 F.2d 284, 295, $5^{\text {th }}$ Circ.1988); no caso, o acordo tem também a participação de anunciantes e agências;

não há violação antitruste em que a autorregulamentação implementa padrões de segurança federais, ou seja, atende à legislação pertinente (Moore $v$ Boating Ind. Associations, 819 F2d 693, 695, $7^{\text {th }}$ Circuit 1987); no caso, o acordo acolhe princípios da legislação referente à propaganda e a implementa;

o acordo deve prever salvaguardas processuais contra decisão que denega uma aprovação (Pretz v Holstein Friesian Ass'n, 698 F.Supp. 1531, 1540, D. Kan. 1988 e Weight Rite Golf Corp v United States Golf Ass'n , 766 F.Supp 1104, 1111, MD. Fla.1991); no caso, o acordo prevê tais salvaguardas.

Também na Alemanha, é reconhecida, por lei (GWB, §28), a possibilidade de se criarem Wirtschafts und Berufsvereinigungen (associações econômicas e profissionais). O conteúdo das regras comuns estabelecidas por tais associações é, usualmente, de normas éticas, sobretudo quanto à lealdade negocial em termos concorrenciais, admitindo-se também regras sobre a formação de preço (Bechtold, 1993:375).

No Brasil, na Lei no 4.680/1965, art. 5o, compreende-se por propaganda "qualquer forma remunerada de difusão de ideias, mercadorias ou serviços, por parte de um anunciante identificado".

No que diz respeito ao detalhamento de princípios e normas, a mesma lei faz uma remissão à autorregulamentação:

Art 17. A atividade publicitária nacional será regida pelos princípios e normas do Código de Ética dos Profissionais da Propaganda, instituído pelo I Congresso Brasileiro de Propaganda, realizado em outubro de 1957, na cidade do Rio de Janeiro. 
No caso do Conar, as limitações estabelecidas impõem a observância de princípios e normas negocialmente instituídas pelos signatários e que valem para eles, desde que em conformidade com a legislação, inclusive o mencionado Código de Ética. Aquelas regras negociais contêm elementos éticos, jurídicos, econômicos e técnicos, na forma de preceitos, cuja infração sujeita os signatários a penalidades éticas, como advertência, recomendação de alteração ou correção do anúncio, recomendação ao veículo para sustar a divulgação do anúncio, bem como a divulgação da posição adotada pelo Conar, quando do não acatamento (Código Brasileiro de Autorregulamentação Publicitária, art. 50). Lembre-se que a regulamentação à propaganda dos produtos referidos no art. 220 da Constituição Federal já está prevista na Lei no 9.294/1996 e que, na forma de autorregulamentação, as normas éticas contidas no Anexo H do Código de Autorregulamentação Publicitária convergem para disciplinar restritivamente a propaganda dos mencionados produtos.

Em especial, no que se refere à criança e ao adolescente, a autorregulamentação de anúncios a eles destinados traduz, portanto, um comando normativo compulsório. Pode-se dizer que suas cláusulas predispostas, gerais e abstratas, passam a constituir um "direito", complementar ao oficial, o que oferece maior flexibilidade às novas necessidades das empresas e que melhor corresponde à dinâmica das relações de mercado no tocante à sua responsabilidade social quanto à propaganda comercial. Na medida em que as condições gerais impostas aos aderentes do acordo dão corpo a um regulamento até mais analítico, exaustivo e claro do que o oferecido pelo direito positivo, são removidos motivos de incerteza e razões de controvérsia, pois nesses termos racionalizam a gestão empresarial, viabilizando a previsão e o cálculo antecipado, com maior aproximação de todos os elementos suscetíveis de figurar como ativo ou passivo no balanço da empresa.

\section{Referências}

AFONSO DA SILVA, Vírgilio. O proporcional e o razoável. Revista dos Tribunais, v. 798, 2002.

ANTITRUST LAW DEVELOPMENTS - ABA. 4. ed., v. I, p. 110-115, 1997.

ÁVILA, Humberto. A distinção entre princípios e regras e a redefinição do dever de proporcionalidade. Revista Diálogo Jurídico, ano I, v. 1, n. 4, jul. 2001.

BECHTOLD, Rainer. GWB - Kartelgesetz - Gesetz gegen Wettbewerbsbeschränkungen, München, 1993.

CANOTILHO, J. J. Gomes. Direito constitucional e teoria da constituição. 2. ed. Coimbra: Almedina, 1998. 
DI PIETRO, Maria Sylvia Zanella. Parcerias na administração pública. São Paulo: Atlas, 2002.

DREIER, Horst et al. Grundgesetz: kommentar. Band I, Art. 19, III, abs. 11. Mohr Siebeck, 1996.

FERRAZ JUNIOR, Tercio Sampaio. Agências reguladoras: legalidade e constitucionalidade. Revista Tributária e de Finanças Públicas, ano 8, n. 35, nov./dez. 2000.

KIRKPATRICK, Jerry. Em defesa da propaganda. São Paulo: Instituto Moreira Salles, 1997.

LOPES, Maria Elizabete Vilaça. O consumidor e a publicidade. Revista de Direito do Consumidor, v. 1, 1992.

MAXIMILIANO, Carlos. Hermenêutica e aplicação do direito. Rio de Janeiro: Forense, 1997.

MENDES, Gilmar. O princípio da proporcionalidade na jurisprudência do Supremo Tribunal Federal. Revista Diálogo Jurídico, ano I, v. 1, n. 5, ago. 2001.

MORAES, Alexandre de. Constituição do Brasil interpretada. São Paulo: Atlas, 2002.

NUSDEO, Fábio. Curso de economia: introdução ao direito econômico. 3. ed. revista e atualizada. São Paulo: Revista dos Tribunais, 2001.

PAZ, Laguna de. Regimen jurídico de la television privada. Madrid: Marcial Pons, 1994.

SILVA, José Afonso da. Curso de direito constitucional positivo. 16. ed. São Paulo: Malheiros, 1999. 